\title{
Does Austria Respond to the German or the US Business Cycle?
}

Yin-Wong Cheung ${ }^{a}$ and Frank Westermann ${ }^{\mathrm{b}, *}$

${ }^{a}$ Economics Board, University of California, Santa Cruz, CA 95064, USA

b Center for Economic Studies, University of Munich, 80539 Munich, Germany

This study assesses the claim that the Austrian economy depends mainly on the German business cycle. Controlling for possible influences from the US economy, it is confirmed that the Austrian and German industrial production indexes have a common long-term stochastic trend and German industrial production Granger-causes the Austrian industrial production in the short run. However, German and US shocks only account for a small proportion of Austrian industrial production variability. Further, it is found that the three countries share a non-synchronized common business cycle. Copyright (C) 2000 John Wiley \& Sons, Ltd.

KEY WORDS: codependence test; cointegration test; common feature test; long-term comovement; non-synchronized common business cycle; output interaction; synchronized business cycles

\section{SUMMARY}

The issue of German influences on its neighbouring European countries has received considerable interest in both academic and political circles. Austria, which shares a common border with Germany, is perceived to be heavily affected by economic developments in Germany. For example, Scherb's (1990) remarks that 'Sachzwang Weltmarkt' for the Austrian case means 'Sachzwang deutscher Markt', which means that the Austrian policy decisions which appear to be reactions to the economic contingencies of the world market are actually 'reactions to the German Market'. Indeed, Austria has maintained close trading ties with Germany and has pegged the schilling to the deutsche mark for the last three decades.

* Correspondence to: Center for Economic Studies, University of Munich, 80539 Munich, Germany.

JEL Code: E32, F42
In this article, we use advanced time series techniques to examine the interactions between Austrian and German output data, controlling for the US effect. It is found that the Austrian, German, and US industrial production indexes tend to move together in the long run. In the short run, Austrian output growth responds to movements in Germany, but not in the US, output. These results are supportive of the claim that Germany affects Austria.

When we evaluate the relative magnitude of the German effect on Austrian output, it is found that German factors contribute little to Austrian output variability. In fact, it is the shocks originated from Austria that are responsible for most of the variation in Austrian output. Even though Germany affects Austria, it is not a dominant factor determining Austrian output movement.

The article also investigates whether these countries share common cyclical movements. We find 
evidence for non-synchronized business cycles. What it means is that business cycles in Austria, Germany, and the US have common components. However, these countries have different initial reactions to a common shock. After the initial phase, these countries have similar responses to a common shock. The dissimilar initial responses may be due to differences in institutional arrangements in these countries and time required for shock propagation.

In sum, there is evidence for German effects on Austria. The output data of these two countries are driven by similar forces in both the long run and short run. However, German output factors are not the main determinants of Austrian output dynamics. A potential future research topic would be to investigate whether the linkages between Germany and Austria are through real or monetary channels and the implication of non-synchronized responses for designing national policies to alleviate the impacts of system shocks.

\section{INTRODUCTION}

Economic developments in Germany have significant implications for its neighbouring countries. In particular, small European countries are closely integrated with the German economy, as shown in Bayoumi and Eichengreen (1993), who consider Germany and her neighbours to be the 'core' of the European Monetary Union. Among the small European countries, the economic ties of Austria to Germany have been perceived to be particularly strong and have received considerable attention recently. For example, Scherb (1990) remarks that 'Sachzwang Weltmarkt' for the Austrian case means 'Sachzwang deutscher Markt', which means that the Austrian policy decisions that appear to be reactions to the economic contingencies of the world market are actually 'reactions to the German Market'. Indeed, Austria has maintained close trading ties with Germany. Even though Austria officially joined the European Union in January 1995, she has pegged the Schilling to the Deutsche Mark for the last three decades.

Empirically, the interaction between the Austrian and German economies is typically analysed by examining the output correlations of these two countries. For example, Winckler (1993) shows that the annual Austrian and German output growth rates are correlated at different lags. He argues that 'the parallel development of macroeconomic variables in Germany and Austria...can hardly be explained by the exportimport link... [it] is probably the outcome of the pragmatic orientation of Austrian policy institutions towards West German economic policy'. Cheung and Westermann (1999) confirm Winckler's results in a bivariate vector error correction model (VECM). Using several macroeconomic indicators, Brandner and Neusser $(1992,1994)$ lend further support to the dependency of Austria on Germany. Brandner and Jaeger (1992) show that Austria is more synchronized with the core of Germany, than most of the German 'Laender' (states in Germany). Markovits (1995) incorporates these findings into a broader discussion of AustroGerman relations. The relations between Austria and Germany are compared and contrasted with those between Canada and the US by von Riekhoff and Neuhold (1993).

This paper examines the Austro-German relation and assesses the dependency of the Austrian economy on the German one. The integration of economies around the world suggests that both Austria and Germany can be affected by and react to some external economic events. To account for possible third party effects, the exercise includes the US economy in evaluating the interaction between Austria and Germany. The US is chosen partly because of its substantial size and its prominent status in the global economy. More importantly, the US is the largest foreign investor and has played an important role on the economic development in Europe since World War II. If both Germany and Austria are responding to economic developments in the US, the world's largest economy, then the influence of Germany on Austria may be spurious and not as strong as it appears. On the other hand, Scherb's statement would be significantly strengthened if one can detect the German effect on Austria even in the presence of the US.

In pursuance of Winckler's argument that policy decisions are the forces behind the interaction between Austrian and German economies, we use industrial production as a proxy for output. In this way we leave out the services sector which, in 
Austria, is largely dominated by the tourism industry. In addition to computing correlations, several advanced time series econometric techniques are used to study various types of co-movements between industrial production in Austria, Germany, and the US. The co-integration technique is used to discern the short-term and long-term output co-movements. The contributions of the German output shocks on Austrian output are assessed using impulse response and forecast error variance decomposition analyses. The recently developed common feature and co-dependence tests are implemented to detect for the presence of common synchronized and non-synchronized cycles among these economies.

To anticipate our results, we find that the Austrian, German, and the US industrial production indexes are co-integrated; i.e. the three national output series move together in the long run. Using the error correction model based on the co-integration result, we show that German output, but not the US output, Granger-causes Austrian output in the short-run. That is, movements in the German output help explain variations in Austrian output. These results are supportive of the claim that Austria is closely related to and affected by Germany and confirm the bivariate results of Cheung and Westermann (1999) in a trivariate model, including the US.

However, as indicated by the forecast error variance decomposition analysis, Austrian shocks are largely responsible for the unexpected variability of Austrian output. Shocks from Germany and the US account for only a small portion of unpredictable Austrian output fluctuations. Furthermore, we find no evidence for synchronized serial correlation cycles. However, the co-dependence test reveals one common non-synchronized serial correlation cycle, indicating that business cycles in Austria, Germany, and the US have a common component, but have different initial reactions to a common shock.

The rest of the paper is organized as follows. The next section presents the preliminary data analysis. The third section reports the co-integration test result and the related error correction model estimation. The fourth section discusses the results from the impulse response and forecast error variance decomposition analyses. The results of testing for common synchronized and non-synchronized business cycles are given in the fifth section. Some concluding remarks finish the paper.

\section{PRELIMINARY ANALYSIS}

Monthly indexes of industrial net production are used as proxies for aggregate output. The sample period covers 1962:1-1994:12. The German data were provided by the Statistisches Bundesamt in Wiesbaden and were seasonally adjusted using the X-11 procedure. The seasonally adjusted US and Austrian data on industrial production were extracted from the OECD database.

The augmented Dickey-Fuller (ADF) test allowing for both an intercept and a time trend to be employed to determine if there is a unit root in the data series. Let $X_{i t}$ be the industrial production index of country $i$ ( $i=$ the US, Germany, and Austria) at time $t$. The ADF test is based on the regression equation

$$
\begin{aligned}
\Delta X_{i t}= & \mu_{0}+\mu_{1} t+\alpha X_{i t-1}+\beta_{1} \Delta X_{i t-1}+\cdots \\
& +\beta_{p} \Delta X_{i t-p}+\varepsilon_{t}
\end{aligned}
$$

where $\Delta$ is the first difference operator and $\varepsilon_{t}$ is an error term. The Akaike information criterion is used to determine $p$, the lag parameter. Results of applying the ADF test to the data and their first differences are shown in Table 1. The null hypothesis of a null root is not rejected for the data series and is rejected for the first differenced data. Thus, there is one unit root in each of the three industrial production series, a result that is consistent with the literature. In the subsequent analysis, we assume the data are difference stationary.

The sample correlation coefficients for the first differenced industrial production data are 0.18

Table 1. Unit root test result

\begin{tabular}{lll}
\hline & Levels & First differences \\
\hline Germany & $-2.22(11)$ & $-10.72^{*}(3)$ \\
Austria & $-1.56(9)$ & $-10.06^{*}(4)$ \\
The US & $-1.75(5)$ & $-7.00^{*}(4)$ \\
\hline
\end{tabular}

Note: The ADF test statistics calculated from the levels and first differences of the industrial production indexes in logs are reported. The lag parameters selected by the Akaike information criterion are in parentheses next to the statistics.

The * indicates significance at the 5\% level. The unit root hypothesis is not rejected for the data series but is rejected for their first differences. 
(Austria and Germany), 0.08 (Austria and the US), and 0.07 (Germany and the US). These sample statistics suggest that the Austrian economy has a closer tie to the German one than to the US. More vigorous analyses of the interactions between these output series are given in the following sections.

\section{LONG-RUN AND SHORT-RUN INTERACTIONS}

The co-integration technique and the implied error correction model are used to study the long- and short-run interactions. The long-run relationship is interesting for, at least, two reasons. First, it indicates whether permanent shocks in the three countries are common or idiosyncratic. Second, information about the long-run behaviour is essential for specifying an appropriate model to analyse short-run interactions. A misspecified long-run relationship can lead to erroneous inferences on short-run dynamics.

\section{Co-integration Test}

The Johansen (1991) procedure is used to test for the presence of co-integration. Let $X_{t}$ be the $3 \times 1$ vector $\left(X_{i t}\right), i=$ the US, Germany, and Austria. The Johansen test statistics are devized from the sample canonical correlations (Anderson, 1958; Marinell, 1995) between $\Delta X_{t}$ and $X_{t-p}$, adjusting for all intervening lags. To implement the procedure, we first obtain the least squares residuals from

$\Delta X_{t}=\mu_{1}+\sum_{i=1}^{p-1} \Gamma_{i} \Delta X_{t-i}+\varepsilon_{1 t}$

and

$X_{t-p}=\mu_{2}+\sum_{i=1}^{p-1} \Gamma_{i} \Delta X_{t-i}+\varepsilon_{21 t}$

where $\mu_{1}$ and $\mu_{2}$ are constant vectors. The lag parameter, $p$, is identified by the AIC. Next, we compute the eigenvalues, $\lambda_{1} \geq \cdots \geq \lambda_{p}$, of $\Omega_{21} \Omega_{11}^{-1} \Omega_{12}$ with respect to $\Omega_{22}$ and the associated eigenvectors, $v_{1}, \ldots, v_{n}$, where the moment matrices $\Omega_{i j}=T^{-1} \Sigma_{t} \hat{\varepsilon}_{i t} \hat{\varepsilon}_{j t}^{\prime}$ for $i, j=1,2$, and $n$ is the dimension of $X_{t}$ (i.e. $n=3$ in this exercise). The $\lambda_{i}$ are the squared canonical correlations between $X_{t}$
Table 2. Co-integration test results

\begin{tabular}{lll}
\hline$H(0)$ & Trace statistic & Maximum eigenvalue statistic \\
\hline$r=0$ & $39.65^{*}$ & $28.75^{*}$ \\
$r \leq 1$ & 11.83 & 9.21 \\
$r \leq 2$ & 1.83 & 1.83 \\
\hline
\end{tabular}

Note: The trace and maximum eigenvalue statistics computed from the trivariate system consisting of German, Austrian and the US production indexes are reported.

The * indicates significance at the $5 \%$ level. The elements of the co-integrating vector are 1 (Germany), -0.97 (Austria), and 0.35 (the US). The $\chi^{2}(1)$ statistics for testing the significance of these elements are, respectively, 14.67, 18.24, and 6.33.

and $X_{t-p}$, adjusting for all intervening lags. The trace statistic,

$t_{r}=-T \sum_{j=r+1}^{n} \ln \left(1-\lambda_{j}\right), \quad 0 \leq r \leq n$,

tests the hypothesis that there are at most $r$ cointegration vectors. In testing the hypothesis of $r$ against the alternative hypothesis of $r+1$ cointegration vectors, we use the maximum eigenvalue statistic,

$\lambda_{r \mid r+1}=-T \ln \left(1-\lambda_{r+1}\right)$.

The eigenvectors $v_{1}, \ldots, v_{n}$ are sample estimates of the co-integration vectors. The Johansen test results are reported in Table 2. Both the trace and maximum eigenvalue statistics suggest there is one co-integrating relationship among the industrial production indexes of these three countries. The estimated co-integrating vector, with the coefficient of the German variable normalized to one, Austrian output as the second variable, and the US output as the third variable, is $(1,-0.97,0.35)$. The sample statistics for testing the null hypothesis that the coefficients are individually zero are, respectively, 14.67, 18.24, and 6.33. Under the null hypothesis, these statistics have an asymptotic $\chi^{2}-(1)$ distribution. Therefore, all three coefficients are statistically significant at the conventional 5\% level. According to the Johansen test, industrial production indexes of the US, Germany, and Austria are co-integrated. These economies experience common permanent shocks, which drive their long-term swings and, thus, share a common long-run component in their industrial production data. Further, the co-integrating coefficients of Germany and Austria are quite similar; indicating that the two industrial production series 
have symmetric influences on the empirical longrun relationship. The result, which has controlled for the possible effect of the US economy, lends a strong support to the view that these two economies are closely linked via some common permanent shocks.

\section{Short-Run Interactions}

Given the co-integration result, we use a vector error correction (VEC) model to explore the effects of short-term variation and deviation from the co-integrating relationship on industrial production indexes. Specifically, the changes in industrial production indexes can be modelled using the following VEC structure:

$\Delta X_{t}=\mu+\sum_{i=1}^{p} \Gamma_{i} \Delta X_{t-i}+\alpha E C_{t-1}+\varepsilon_{t}$

where $E C_{t}$ is the error correction term given by $\beta^{\prime} X_{t}$ and $\beta$ is the cointegrating vector. The responses of industrial production to short-term output movements are captured by the $\Gamma_{i}$ coefficient matrices. The $\alpha$ coefficient vector reveals the speed of adjustment to the error correction term, which measures the deviation from the long-run relationship between the industrial production indexes. Coefficient estimates of the VEC model are presented in Table 3. The German and Austrian industrial production changes have asymmetric effects on each other. In the presence of the US variable, all the three lagged German industrial production terms help explain movements in Austrian output. The coefficients are both positive and significant. That is, an increase in German output is likely to be followed by an upward swing in the Austrian output. On the other hand, the German variable is not explained by any lagged changes in Austrian industrial production. Interestingly, the Austrian economy appears not to be affected by developments in the US economy. Using the Granger causality terminology, the German industrial production causes the Austrian one. Further it is noted that the error correction term in both the German and Austrian equations is significantly different from zero, indicating that both economies respond to deviations from the equilibrium relationship that governs the long run co-movement of their industrial production.
Table 3. The vector error correction model

\begin{tabular}{|c|c|c|c|}
\hline & The US & Germany & Austria \\
\hline$\Delta X_{\text {(The US, } t-1)}$ & $\begin{array}{l}0.30^{*} \\
(0.05)\end{array}$ & $\begin{array}{l}0.39^{*} \\
(0.12)\end{array}$ & $\begin{array}{c}0.16 \\
(0.13)\end{array}$ \\
\hline$\Delta X_{\text {(The US, } t-2)}$ & $\begin{array}{c}0.10^{*} \\
(0.05)\end{array}$ & $\begin{array}{r}0.10 \\
(0.13)\end{array}$ & $\begin{array}{r}0.12 \\
(0.14)\end{array}$ \\
\hline$\Delta X_{\text {(The US, } t-3)}$ & $\begin{array}{r}0.07 \\
(0.05)\end{array}$ & $\begin{array}{r}-0.10 \\
(0.12)\end{array}$ & $\begin{array}{r}0.09 \\
(0.13)\end{array}$ \\
\hline$\Delta X_{(\text {Germany, } t-1)}$ & $\begin{array}{r}0.00 \\
(0.01)\end{array}$ & $\begin{array}{c}-0.66^{*} \\
(0.04)\end{array}$ & $\begin{array}{c}0.12^{*} \\
(0.05)\end{array}$ \\
\hline$\Delta X_{(\text {Germany }, t-2)}$ & $\begin{array}{r}0.02 \\
(0.02)\end{array}$ & $\begin{array}{c}-0.32^{*} \\
(0.05)\end{array}$ & $\begin{array}{l}0.20^{*} \\
(0.05)\end{array}$ \\
\hline$\Delta X_{(\text {Austria }, t-3)}$ & $\begin{array}{c}0.03^{*} \\
(0.01)\end{array}$ & $\begin{array}{r}-0.00 \\
(0.04)\end{array}$ & $\begin{array}{c}0.17^{*} \\
(0.05)\end{array}$ \\
\hline$\Delta X_{(\text {Austria }, t-1)}$ & $\begin{array}{c}-0.01 \\
(0.01)\end{array}$ & $\begin{array}{c}-0.01 \\
(0.04)\end{array}$ & $\begin{array}{c}-0.63^{*} \\
(0.05)\end{array}$ \\
\hline$\Delta X_{(\text {Austria }, t-2)}$ & $\begin{array}{r}0.02 \\
(0.02)\end{array}$ & $\begin{array}{c}0.01 \\
(0.05)\end{array}$ & $\begin{array}{c}-0.32^{*} \\
(0.05)\end{array}$ \\
\hline$\Delta X_{(\text {Austria }, t-3)}$ & $\begin{array}{r}-0.00 \\
(0.01)\end{array}$ & $\begin{array}{r}-0.02 \\
(0.04)\end{array}$ & $\begin{array}{c}-0.14^{*} \\
(0.05)\end{array}$ \\
\hline$E C_{(t-1)}$ & $\begin{array}{r}0.00 \\
(0.73)\end{array}$ & $\begin{array}{c}-0.18^{*} \\
(0.01)\end{array}$ & $\begin{array}{c}0.04^{*} \\
(0.02)\end{array}$ \\
\hline Adjusted $R^{2}$ & 0.15 & 0.45 & 0.28 \\
\hline
\end{tabular}

Note: Coefficients of the VEC models are reported. Heteroskedasticity consistent standard errors are given in parentheses.

The ${ }^{*}$ indicates significance at the $5 \%$ level.

So far, the empirical results are in accordance with the view that there are close linkages between the German and Austrian economies. The two economies share a common trend in the longrun industrial production. On short-term variation, the Austrian economy appears to systematically respond to changes in German industrial output. Put the results together, there seems convincing evidence that the Austrian policies are mainly oriented toward the German ones and not policies pursued in, for example, the US, which is believed to have substantial influence on the world economy in general

\section{Impulse Responses and Forecast Error Variance Decomposition}

To obtain a better understanding of the effects of output shocks on Austria, we use the VEC model reported above to compute the cumulative impulse responses of Austrian industrial production to one standard deviation shocks. The rankings of the variables are the US, Germany, and Austria. The impulse responses mirror the coefficients of 
the moving average representation of the VEC model and track the effects of a shock on the endogenous variables at a given point of time. The impulse responses are graphed in Figure 1. It is evidenced that the industrial production in Austria responds more to shocks emanating from Austria than those from the US and Germany. Consistent with the VEC model estimation results, output shocks originated from the US have virtually no impact on Austria. The effects of German output shocks appear to be short-lived and last only for a few months.

While the impulse responses provide information on the effect of a standardized output shock, they do not indicate the extent to which a given shock contributes to the level of uncertainty in the Austrian industrial output. To further assess the relative importance of output shocks, we decompose the Austrian industrial output forecast error variance into parts that are attributable to shocks emanating from the US, Germany, and Austria.

The proportions of the Austrian industrial output forecast error variance are graphed in Figure 2. For the horizons under consideration, the US shock accounts for a very small percentage of the total forecast error variance. Output shocks from Austria and Germany account for, approximately, $90 \%$ and $10 \%$ of the forecast uncertainty. That is, the uncertainty in Austrian industrial output growth is mainly generated by shocks to its economy. External shocks, either from the US or Germany, play a limited role in determining Austrian output uncertainty.

Despite the close ties between Austria and Germany revealed by the co-integration technique and the VEC model, the impulse response and the forecast error variance decomposition results manifest that Austrian, and not German, output shocks are the driving forces behind the Austrian output variability and uncertainty. While German output Granger-causes Austrian output, German shocks only contribute to a relatively small portion of Austrian output fluctuations.

\section{COMMON BUSINESS CYCLE}

For non-stationary series, co-integration describes the co-movement between long-run non-stationary stochastic trends. The co-movement among
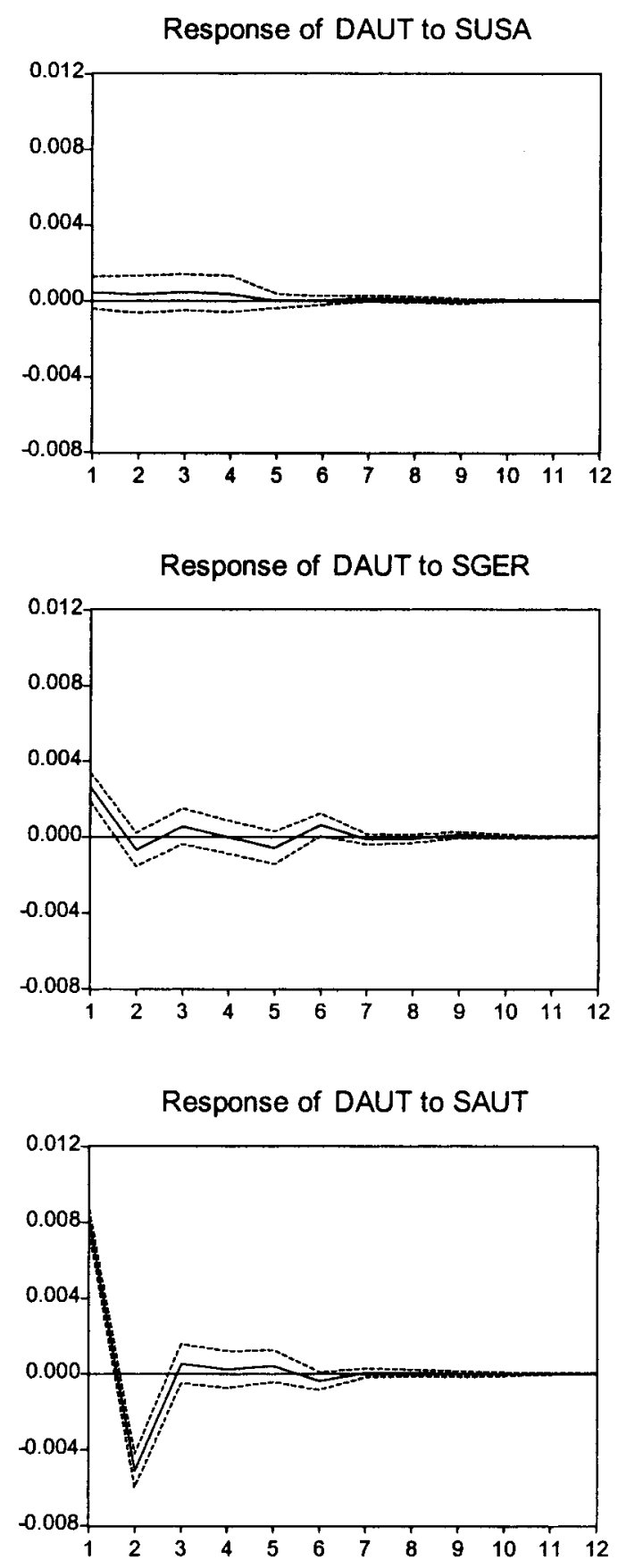

Figure 1. Impulse responses of Austrian industrial production to Austrian, German, and the US shocks. Note: The solid lines trance the impulse responses of Austrian (DAUT) industrial production growth to Austrian (SAUT), German (SGER) and the US (SUSA) shocks. The two-standard error confidence intervals (dotted lines) are generated by 1000 Monte Carlo replications. 


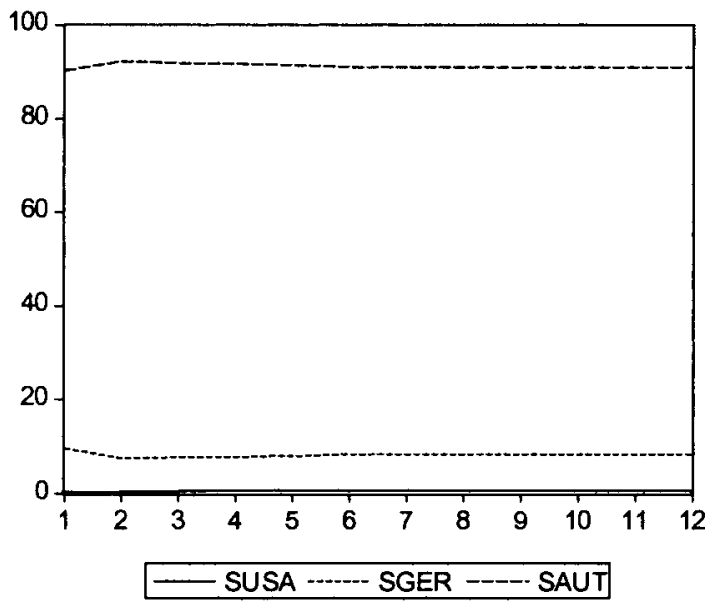

Figure 2. Forecast error variance decomposition for the Austrian industrial production. Note: The proportions of the forecast error variance of the Austrian industrial production ascribed to Austrian, German, and the US shocks are traced by the lines labelled SAUT, SGER, and SUSA.

stationary series can be examined using the concept of common features (Engle and Kozicki, 1993). The intuition behind the common feature analysis is as follows. Suppose the temporal dynamics of $\left(\Delta X_{i t}\right), i=$ the US, Germany, and Austria, are driven by a common stochastic process. The effect of this common stochastic component can be removed by choosing an appropriate linear combination of $\Delta X_{i}$. Thus, the presence of a common serial correlation cycle implies the existence of a linear combination of $\Delta X_{i}$ that is not correlated with the past information set. For a system of co-integrated series, a test for common features among the stationary components has to allow for the effect of long-term co-movements as indicated by the co-integration relationship. Vahid and Engle (1993) devised such a procedure to test for common serial correlation features in the presence of co-integration. The procedure amounts to finding the sample canonical correlations between $\Delta X_{t}$ and $W(p) \equiv\left(\Delta X_{t-1}^{\prime}, \ldots, \Delta X_{t-p}^{\prime}, E C_{t-1}\right)^{\prime}$. Specifically, the test statistic for the null hypothesis that the number of co-feature vectors is at least $s$ is

$C(p, s)=-(T-p-1) \sum_{j=1}^{s} \ln \left(1-\lambda_{j}\right)$

where $\lambda_{n} \geq \cdots \geq \lambda_{1}$ are the squared canonical correlations between $\Delta X_{t}$ and $W(p)$ and $n$ is the dimension of $\Delta X_{t}$ (i.e. $n=3$ in this exercise). When $s$ is the dimension of the co-feature space, $n-s$ is the number of common cycles. Under the null hypothesis, the statistic $C(p, s)$ has an $\chi^{2}$ distribution with $s+s n p+s r-s n$ degrees of freedom, where $r$ is the number of error correction terms included in $W(p)$. See Vahid and Engle (1993) for a detailed discussion of the statistics.

The common serial correlation feature test results are presented in Table 4. Given the lag structure reported in the previous sections, the common feature test is conducted with $p=3$. Since all the statistics are significant, there is no evidence that the US, Germany, and Austria share a common serial correlation feature among their industrial production indexes. Bivariate test results also confirm the absence of a common feature in these data. As cyclical variations in industrial output are typically modelled by its serial correlation pattern, the test result suggests that these countries do not share a common business cycle and corroborates the findings reported in Campbell and Mankiw (1989) and Cheung (1994) that national business cycles are not alike.

The absence of co-movements among the industrial production growth rates appears surprising. In the previous section, we find that the industrial production indexes in the US, Germany, and Austria have a common long-swing element that drives their long-run dynamic behaviour. In the

Table 4. Test for common features

\begin{tabular}{llcc}
\hline Null hypothesis & Squared canonical correlation & Statistic $C(p, s)$ & Degree of freedom \\
\hline$s \geq 1$ & 0.20 & $88.42^{*}$ & 8 \\
$s \geq 2$ & 0.32 & $242.91^{*}$ & 18 \\
$s \geq 3$ & 0.35 & $415.58^{*}$ & 30 \\
\hline
\end{tabular}

Note: The common feature test results are reported. The degree of freedom of the $C(p, s)$ is calculated with $n=3$, $p=3$ and $r=1$.

The ${ }^{*}$ indicates significance at the $5 \%$ level. 
Table 5. Test for co-dependence

\begin{tabular}{llcc}
\hline Null hypothesis & Squared canonical correlation & Statistic $C(k, p, s)$ & Degree of freedom \\
\hline$s \geq 1$ & 0.002 & 1.12 & 5 \\
$s \geq 2$ & 0.05 & $21.82^{*}$ & 12 \\
$s \geq 3$ & 0.16 & $91.07^{*}$ & 21 \\
\hline
\end{tabular}

Note: The co-dependence test results are reported. The degree of freedom of the $C(k, p, s)$ is calculated with $n=3$, $k=1, p=2$, and $r=1$.

The ${ }^{*}$ indicates significance at the 5\% level. The elements of the co-dependence vector are 1 (the US), 0.060 (Germany), and 0.068 (Austria). The asymptotic $t$-statistics for these co-dependence coefficients are, respectively, 8.24, 10.53, and 68.0.

short-term, the Austrian output growth responds to changes in German output. These results seem contradictory to the finding that these countries do not have a common business cycle.

However, the concept of common features is a measure of contemporaneous co-movements and it imposes a strong assumption on the way variables respond to shocks. To share a common serial correlation feature, the variables have to respond to the shocks simultaneously. If one of the variables in the system has a delayed response to a given shock, there will be no common feature. Because of institutional differences and time required for shock propagation, it is likely that Austria will respond to a shock emanated from, for example, Germany with a time lag. The delay in response can occur even though Austria will react fully to the shock in later periods. Thus, the common feature test result, which indicates the absence of synchronized responses to shocks, may not be inconsistent with the evidence on the interactions between the output series reported in the previous section.

To assess if there exists a common but non-synchronized business cycle among the three industrial production output series, we employ the recently developed co-dependence test (Vahid and Engle, 1997). A system of time series is codependent if the impulse responses of the variables are collinear beyond a certain period. That is, co-dependence allows the series to have different initial responses to a shock but requires them to share a common response pattern after the initial stage. Without restricting the initial effects on the variables, the notion of co-dependence makes it operationally feasible to model non-synchronized business cycles.
The co-dependence test is a generalization of the common feature test, which requires the variables to have collinear impulse responses for all periods. A common feature is co-dependence with the initial period equal to an empty set. To test for the null hypothesis that there exists at least $s$ codependence vectors after the $k$ th period, we employ the following statistic (Vahid and Engle, 1997):

$\mathfrak{J}(k, p, s)=-(T-p-1) \sum_{j=1}^{s} \ln \left\{1-\left[\lambda_{j}(k) / d_{j}(k)\right]\right\}$,

where $\lambda_{n}(k) \geq \cdots \geq \lambda_{1}(k)$ are the squared canonical correlations between $\Delta X_{t}$ and $W(k, p) \equiv\left(\Delta X_{t-k-1}^{\prime}\right.$, $\left.\ldots, \Delta X_{t-k-1}^{\prime}, \ldots, \Delta X_{t-k-p}^{\prime}, E C_{t-k-1}\right)^{\prime}, n$ is the dimension of $\Delta X_{t}$ (i.e. $n=3$ in this exercise), and $d_{j}(k)$ is given by

$d_{j}(k)=1 \quad$ for $k=0$,

and

$d_{j}(k)=1+2 \sum_{v=1}^{k} \rho_{v}\left(\alpha^{\prime} \Delta X_{t}\right) \rho_{v}\left(\gamma^{\prime} W(k, p)\right), \quad$ for $\geq 1$,

where $\rho_{v}\left(z_{t}\right)$ is the sample autocorrelation of $z_{t}$ at the $v$ th lag, $\alpha$ and $\gamma$ are the canonical variates corresponding to $\lambda_{j}(k)$. Note that when $k=0$, the co-dependence test statistic $\mathfrak{J}(k, p, s)$ is reduced to the common feature test statistic $C(p, s)$. Under the null hypothesis, the statistic $C(k, p, s)$ has an $\chi^{2}$ distribution with $s+s n p+s r-s n$ degrees of freedom, where $r$ is the number of error correction terms included in $W(k, p)$.

If there is co-dependence for $k=1$, then there is co-dependence for $k>1$. Thus, we first test for co-dependence in the series with $k=1$. Given the lag structure reported in the previous sector, we set the maximum lag in the instrumental variable 
list $W(k, p)$ to 3 . The results of using the codependence test to detect for non-synchronized business cycles are reported in Table 5 .

The test statistics indicate that the three countries share non-synchronized business cycles as one co-dependence relationship is found. Aside from the first period reaction, the responses of the industrial production indexes to shocks are 'linearly dependent' and a linear combination of the indexes, as given by the co-dependence vector, is unpredictable with respect to the history of the indexes themselves. Since output indexes are driven by two common cyclical elements. That is, the short-term output variations in these countries are not independent from each other and they share two common cyclical components. The elements of the co-dependence vector, as reported in Table 5, are all significantly different from zero. Analogous to the case of co-integrating coefficients, the German and Austrian variables have similar co-dependent coefficients, implying that the two national industrial production indexes contribute to the co-dependent relationship in a parallel manner. This again evinces the resemblance of the German and Austrian output dynamics.

Hochreiter and Winckler (1995) attest that there was a change in Austrian monetary policy from a 'soft' to a 'hard currency peg' in 1980. Such a change may imply a higher degree of comovement between business cycles in the two countries. To investigate this possibility, we apply the common feature and co-dependence tests to two sub-sample periods-1962:1-1979:12 and 1980:1-1994:12.

For both sub-sample periods, the test statistic $C(p, s)$ strongly rejects the null hypothesis of common features; indicating there is no common feature; i.e. no synchronized common business cycle between the national industrial production indexes $^{1}$. On the other hand, the statistic $C(k, p, s)$ confirms that there is co-dependent between the industrial production indexes before and after $1980^{2}$. Specifically, aside from reactions in the first period, the response patterns of the industrial production indexes to shocks are quite similar in the pre- and post-1980 periods. While Austria has pursued a more stringent exchange rate policy after 1980, we do not detect a significant change in the co-movements in the Austrian and German business cycles. However, it is possible that the statistical techniques used may not be powerful to unveil the change in the co-movement pattern.

\section{CONCLUDING REMARKS}

Using advanced time series econometric techniques, we study the interaction between the German and Austrian economies controlling for the influence of the US economy. Industrial production is used as a proxy for aggregate output. Austria and Germany are found to share common permanent stochastic shocks that drive the longrun fluctuations of their industrial output. In the short-run, Austrian industrial output is Grangercaused by the German one. Nonetheless, there is no evidence that the US economy affects the Austrian industrial output in the short-run. This finding is supportive of the claim that the German economy has substantial influences on the Austrian economy. The German effect experienced by Austria is likely to be a manifestation of the exchange rate peg between the two countries and the likelihood that the Austrian industrial policy is heavily adapted towards the German one.

The impulse response and forecast error variance analysis, on the other hand, indicate that the effects of German output shocks on Austria tend to be short-lived and the Austrian output uncertainty is largely attributable to shocks to its own economy. Thus, in light of this finding, one should qualify the German influences on Austria. Derived from the exchange rate arrangement and trade activity, the Austrian and German economies are closely linked and the former one appears to react to the latter. However, shocks to Austria itself are mainly responsible for the unexpected variations in the Austrian output. A potential future research project is to investigate whether the linkages between Germany and Austria are through real or monetary channels.

The study of common business cycles shows that these countries do not have simultaneous cyclical co-movements. However, they share common non-synchronized business cycles. That is, these countries have different initial responses to shocks to the system though they tend to react fully in the subsequent periods. Differences of national institutional factors and time required to 
transmit shocks across boundaries are the possible reasons for non-synchronized initial responses. It will be an interesting research topic to investigate the implication of non-synchronized responses for designing national polices to alleviate the impacts of system shocks.

\section{ACKNOWLEDGEMENTS}

The authors would like to thank Peter Brandner, Klaus Neusser, Andrei Markovits, Jürgen Schröder, Georg Winckler, and participants of the 1998 EMU and the outside World Conference (hosted by the Institute for Business Cycle Research at the University of Zurich, Switzerland) and of the Privatissimum-Seminar at the University of Vienna for their helpful comments on earlier versions of the paper. This research was supported by the CGES at UC Berkeley and UC Santa Cruz faculty research funds.

\section{NOTES}

1. For the pre-1980 sub-sample, the $C(p, s)$ statistics for the hypotheses $s>1, s>2$, and $s>3$ are 34.79, 66.97, and 156.57, respectively. For the post-1980 subsample, the $C(p, s)$ statistics for the hypotheses $s>1$, $s>2$, and $s>3$, are 24.82, 74.93, and 156.29, respectively. Test results based on bivariate systems also reject the null hypotheses of common features.

2. For the pre-1980 sub-sample, the $\mathfrak{I}(k, p, s)$ statistics for the hypotheses $s>1, s>2$, and $s>3$ are 1.47, 10.29 , and 52.51, respectively. For the post-1980 subsample, the $\mathfrak{I}(k, p, s)$ statistics for the hypotheses $s>$ $1, s>2$, and $s>3$ are 3.34, 17.19, and 37.67, respectively.

\section{REFERENCES}

Anderson, T.W., An Introduction in Multivariate Statistical Analysis, New York: Wiley, 1958.

Bayoumi, T. and Eichengreen, B., 'Shocking Aspects of a European Monetary Union', in F. Torres and F. Giavazzi (Eds), Adjustment and Growth in the European Monetary Union, Cambridge: Cambridge University Press, 1993, pp. 193-229.

Brandner, P. and Jaeger, A., Zinsniveau und ZinsstruLtur in Oesterreich, Wien: Austrian Institute for Economic Research, 1992, pp. 39-49.
Brandner, P. and Neusser, K., 'Business Cycles in Open Economies: Stylized Facts for Austria and Germany', Weltwirtschaftliches Archiv, 128 (1992), 67-87.

Brandner, P. and Neusser, K., 'Business Cycles in Open Economies: A Reply', Weltwirtschaftliches Archiv 130 (1994), 631-633.

Campbell, J. and Mankiw, N.G., 'International Evidence on the Persistence of Economic Fluctuations', Journal of Monetary Economics 23 (1989), 319-333.

Cheung, Y.-W., 'Aggregate Output Dynamics in the Twentieth Century', Economics Letters 45 (1994), 15-22.

Cheung, Y.-W. and Lai, K.S., 'Finite Sample Sizes of Johansen's Likelihood Ratio Tests for Cointegration', Oxford Bulletin of Economics and Statistics 55 (1993), 313-328.

Cheung, Y.-W. and Westermann, F., 'An Analysis of German Effects on the Austrian Business Cycle', Weltwirtschaftliches Archiv 135(3) (1999), forthcoming.

Engle, R.F. and Kozicki, S., 'Testing for Common Features', Journal of Business and Economics Statistics 11 (1993), 369-379.

Hochreiter, E. and Winckler, G., 'The Advantages of Tying Austria's Hands: The Success of the Hard Currency Strategy', European Journal of Political Economy 11 (1995), 83-111.

Johansen, S., 'Estimation and Hypothesis Testing of Cointegration Vectors in Gaussian Vector Autoregressive Models', Econometrica 59 (1991), 1551-1581.

Markovits, A.S., 'Austrian-German Relations in the New Europe: Predicaments of Political and National Identity Formation', German Studies Review XIX (1996), 91-111.

Marinell, G., Multivariate Verfahren, Oldenbourg: Muenchen, 1995.

Scherb, M., 'Die Beziehungen zwischen Österreich und der Bundesrepublik Deutschland in den Bereichen Währung, Aussenhandel und Direktinvestiton, in dies. und Inge Morawetz (Eds), In deutscher Hand? Österreich und sein Grosser Nachbar, Wien: Verlag für Gesellschaftskritik, 1990, p. 55.

Torres, F. and Giavazzi, F. (Eds), Adjustment and Growth in the European Monetary Union, Cambridge: Cambridge University Press, 1993.

Vahid, F. and Engle, R.F., 'Common Shocks and Common Cycles', Journal of Applied Econometrics 8 (1993), 341360 .

Vahid, F. and Engle, R.F. 'Codependent Cycles', Journal of Econometrics 80 (1997), 199-221.

von Riekhoff, H. and Neuhold, H. (Eds), Unequal Partners: A Comparative Analysis of Relations Between Austria and the Federal Republic of Germany and Between Canada and the United States, Boulder, CO: Westview Press, 1993.

Winckler, G., 'The Impact of the Economy of the FRG on the Economy of Austria', in H. von Riekhoff and $\mathrm{H}$. Neuhold (Eds), Unequal Partners: A Comparative Analysis of Relations Between Austria and the Federal Republic of Germany and Between Canada and the United States, Boulder, CO: Westview Press, 1993. 